\title{
SOSIALISASI DAN PEMANFAATAN TANAMAN REFUGIA SEBAGAI ALTERNATIF PENGENDALI HAMA TANAMAN
}

\author{
Ilhamiyah ${ }^{1}$, Gusti Khairun Ni’mah ${ }^{1}$, Ana Zuraida ${ }^{1}$, dan Neni Widaningsih ${ }^{2}$ \\ ${ }^{1)}$ Program Studi Agribisnis, Fakultas Pertanian,Universitas Islam Kalimantan \\ ${ }^{2)}$ Program Studi Peternakan, Fakultas Pertanian, Universitas Islam Kalimantan \\ E-mail : iililhamiyah@gmail.com
}

\begin{abstract}
The problem faced by farmers who are members of Gapoktan in the Karang Bunga Village, Mandastana District, Barito Kuala Regency in rice cultivation is pest attack. Farmers always control pest attacks using synthetic pesticides. This causes rice production to be unsafe for consumption because it contains pesticide residues, and can cause the death of natural enemies, resurgence and resistance to pesticides. Therefore it is necessary to conduct socialization and utilization of refugia plants for the conservation of natural enemies and pest control by paying attention to ecological, economic and cultural aspects to create a sustainable agricultural system by suppressing environmental pollution by synthetic pesticides. The method used is to conduct socialization and utilization of refugia plants as agents for controlling pests of rice that are environmentally friendly in the form of socialization through counseling, discussion and demonstration on rice farmers' land. The results of PPM activities are an increase in PPM participant knowledge in terms of knowledge about the use of refugia plant technology; PPM participants gain skills in utilizing refugia plant technology; some PPM participants have started utilizing refugia plant technology by planting rice fields with paper flowers (Zinnia elegans Jaqc)
\end{abstract}

Keywords : refugia, resistance, natural enemies

\section{PENDAHULUAN}

\section{Analisis Situasi}

Dalam budidaya tanaman padi, salah satu masalah yang dihadapi petani adalah serangan hama. Berdasarkan hasil survey hampir semua petani padi untuk mengendalikan hama selalu menggunakan pestisida sintetik. Petani dalam menggunakan pestisida sintetik selalu dengan frekuensi aplikasi dan dosis yang tinggi sehingga berdampak negative seperti matinya musuh alami, menimbulkan residu, matinya serangga bukan sasaran, resurgensi, pencemaran lingkungan baik tanah, air dan udara. Dampak negative tersebut dapat dikurangi melalui Pengendalian Hama Terpadu (PHT) dengan memanfaatkan agen hayati. Rekayasa ekologi berupa pemanfaatan tanaman refugia berperan sebagai mikrohabitat agen hayati dari OPT tanaman utama. Refugia dapat menyediakan tempat berlindung secara spasial dan/atau temporal bagi musuh alami hama, seperti predator dan parasitoid, 
serta mendukung komponen interaksi biotik pada ekosistem, seperti polinator. Beberapa tanaman refugia yang dapat digunakan sebagai agen hayati dari OPT tanaman padi antara lain: bunga matahari (Helianthus annuus), bunga kertas zinnia (Zinnia elegans), kenikir (Cosmos caudatus). Sayuran yang berpotensi sebagai refugia sekaligus bahan pangan antara lain kacang panjang (Vigna unguculata spp), bayam ( Amaranthus sp), jagung (Zea mays) dan lain-lain. Modifikasi lahan pada sistem tanam polikultur menggunakan tanaman refugia dapat dilakukan melalui inter cropping, strip cropping, alley cropping, tanaman pinggiran (hedgerows), insectary plant, beetle bank, tumbuhan mulsa hidup, dan tanaman penutup tanah (cover crop).

Salah Satu Gapoktan (Gabungan Kelompok Tani) yang ada di Desa Karang Bunga Kecamatan Mandastana Kabupaten Barito Kuala adalah Gapoktan Bunga Karang selaku Mitra. Tanaman padi dan jeruk merupakan tanaman unggulan yang diusahakan di desa tersebut. Rata-rata petani di desa tersebut tidak mengetahui teknik pengendalian yang lain untuk mengendalikan hama tanaman padi kecuali dengan menggunakan pestisida sintetik (Kimia) yang memberikan dampak negative baik bagi petani, konsumen dan lingkungan.

Berdasarkan analisis situasi tersebut di atas kiranya perlu dilakukan sosialisasi dan pemanfaatan tanaman/tumbuhan refugia sebagai agen pengendali hama yang ramah lingkungan. Salah satu bagian dalam berusaha tani padi yang perlu dibina adalah dalam hal pengendalian hama secara terpadu yang mempertimbangkan faktor ekologi yang dikenal dengan istilah Pengendalian Hama Terpadu (PHT). PHT menitikberatkan pemanfaatan berbagai teknik pengendalian yang dikombinasikan dalam satu kesatuan program, sehingga dicapai keuntungan ekonomi yang maksimal, dan memberikan dampak yang aman bagi pekerja, konsumen dan lingkungan hidup. Secara prinsip, berbagai cara pengendalian diterapkan harus secara teknis efektif dan dapat diterapkan, secara ekonomi menguntungkan, secara ekologi aman dan secara sosial budaya dapat diterima (Prabaningrum 2015).

Pengendalian hama dengan cara rekayasa ekologi dengan memanfaatkan tanaman/tumbuhan refugia yang berfungsi untuk berlindung sementara 
dan penyedia tepung sari untuk makanan alternatif predator, jika mangsa utama populasinya rendah atau tidak ada di pertanaman pokok. Penanaman tanaman refugia dapat mendorong konservasi musuh alami seperti predator (Mahmud, 2006).

\section{Identifikasi dan Perumusan Masalah} Mitra

$\begin{array}{crr}\text { Berdasarkan } & \text { hasil survey } \\ \text { pendahuluan oleh } & \text { Tim } & \text { PPM, }\end{array}$
permasalahan yang dihadapi oleh Mitra adalah

1. Adanya serangan hama dalam budidaya tanaman padi. Serangan hama kalau dibiarkan dapat menyebabkan kehilangan hasil sampai $100 \%$. Petani padi di Gapoktan Bunga Karang selalu mengendalikan hama dengan menggunakan pestisida sintetik (kimia). Penggunaan pestisida sintetik (kimia) oleh petani dilakukan secara tidak bijaksana artinya tidak sesuai dosis anjuran dan terus menerus bahkan mencampur beberapa jenis pestida. Usaha pengendalian hama tersebut sematamata hanya ditujukan untuk memusnahkan organisme pengganggu tanaman, tanpa memperhatikan kaidah-kaidah ekologi seperti keseimbangan dan kestabilan ekosistem. Oleh karena itu cara pengendalian hama semacam ini harus segera ditinggalkan dan beralih ke konsep pengelolaan hama yang berwawasan ekologi (Mahmud T. 2006).

2. Petani hanya mengenal pengendalian hama tanaman padi dengan menggunakan pestisida sintetik (kimia) sedangkan rekayasa ekologi dengan memanfaatkan tanaman/tumbuhan refugia sama sekali belum mengetahui nya apalagi memanfaatkannya sebagai agen pengendali hama tanaman padi.

Hal ini disebabkan karena kurangnya pengetahuan petani tentang dampak penggunaan pestisida sintetik terutama bagi produk tanaman padi, lingkungan bahkan kesehatan petani itu sendiri. Oleh karena itu sangat perlu dilakukan pembinaan petani dalam pengendalian hama secara terpadu dengan menggunakan tanaman/tumbuhan refugia. Penggunaan tanaman/tumbuhan refugia sangat bermanfaat karena mempunyai kemampuan memikat banyak serangga dan jasad pemanfaat tumbuhan lainnya, dan memiliki banyak manfaat bagi 
jasad-jasad ini, misalnya sebagai sumber pakan maupun tempat perhentian (untuk meletakkan telur atau menyembunyikan diri dari bahaya). Fungsi yang beragam ini menyebabkan pentingnya memperhatikan tumbuhan refugia sebagai habitat khusus bagi serangga dan jasad lainnya. Adanya tumbuhan refugia akan mengundang berbagai organisme yang dalam ekosistem tersebut memiliki bermacammacam peran selain sebagai herbivora, misalnya sebagai musuh alami, polinator atau fungsi ekologis lainnya. Keberagaman fauna karena adanya tanaman berbunga akan menyebabkan terbentuknya ekosistem yang lebih stabil, yang pada gilirannya akan menjaga terjadinya keseimbangan komponen ekosistem. Kehadiran tumbuhan refugia dengan demikian sangat penting untuk melestarikan populasi musuh alami di suatu ekosistem seperti agroekosistem.

\section{Tujuan}

Tujuan dari Program Pemberdayaan Masyarakat (PPM) adalah memberikan ilmu pengetahuan, keterampilan dan teknologi kepada Gapoktan Bunga Karang agar dapat mengendalikan serangan hama pada tanaman padi yang di budidayakan petani dengan memperhatikan aspekaspek ekologi, ekonomi dan budaya serta kerusakan lingkungan secara umum dengan pemanfaatan teknologi tanaman refugia untuk konservasi musuh alami dan pengendalian hama secara hayati.

\section{METODE PELAKSANAAN}

Metode Pelaksanaan Kegiatan

Tim Pelaksanaan PPM menyampaikan secara bertahap kepada pengurus dan anggota Gapoktan Bunga Karang bahwa setiap inovasi yang diterima oleh Mitra harus melalui proses mendengarkan, melihat, mencoba, mengevaluasi, menerima, meyakini dan melaksanakan. Inovasi berupa teknologi tersebut diharapkan dapat diterima dan dilaksanakan secara berkelanjutan bahkan mampu mengembangkannya.

Penyampaian setiap proses inovasi supaya dapat diterima dan dilaksanakan dengan baik oleh Mitra sebagai target sasaran, maka Tim Pelaksana PPM menyampaikan solusi permasalahan Mitra (Rachmawati et al., 2019 dan Rostini et al., 2019) sebagai berikut: 
1. Sosialisai melalui penyuluhan secara umum dalam pengendalian hama mencakup :

Rekayasa ekologi dengan memanfaatkan tanaman/tumbuhan refugia sebagai agen pengendali yang aman bagi petani, konsumen dan lingkungan sebagai agen pengendali hama tanaman padi

2. Diskusi

3. Demonstrasi

Dilakukan bersama petani di lahan persawahan dengan cara membuat lahan percontohan, agar petani dapat melihat dan membuktikan terhadap objek yang didemontrasikan.

4. Pendampingan

Pendampingan dilakukan kepada Gapoktan Bunga Karang sampai petani merasakan manfaat dari penggunaan tanaman/tumbuhan refugia.

Sebelum kegiatan PPM dilaksanakan, terlebih dahulu dilakukan pre tes untuk mengetahui tingkat pengetahuan dan kompetensi Mitra dan pada akhir kegiatan dilakukan pos tes untuk mengetahui tingkat penyerapan ilmu pengetahuan dan teknologi yang disampaikan oleh Tim PPM.

\section{Pelaksanaan Kegiatan}

Kegiatan PPM dilaksanakan di ruang pertemuan Gapoktan Bunga Karang dan di lahan petani. Khalayak sasaran yang akan hadir berasal dari pengurus dan anggota Gapoktan Bunga Karang.

Metode penyuluhan yang digunakan adalah metode ceramah tentang hama tanaman padi dan tanaman/tumbuhan refugia sebagai agen pengendali hama tanaman padi disampaikan oleh tim pengabdian kepada masyarakat, kemudian dilanjukan dengan diskusi.

Untuk kegiatan demostrasi dilaksanakan bersama-sama dengan petani, sedangkan pelaksanaannya dibagi dua kegiatan, Pertama penjelasan tentang pemanfaatan tumbuhan/tanaman refugia sebagai alternatif pengendalihan Organisme Pengganggu Tanaman (OPT) yang ramah lingkungan.tan Pengabdian Kepada Masyarakat.

HASIL

PELAKSANAAN

KEGIATAN

Sosialisasi Melalui Penyuluhan

Sosialisasi merupakan kegiatan awal dari pengabdian kepada masyarakat yang dilaksanakan oleh Tim 
Program Pemberdayaan Masyarakat. Tujuan dari Program Pemberdayaan Masyarakat (PPM) adalah memberikan ilmu pengetahuan, teknologi agar dapat mengendalikan serangan hama tanaman padi yang di budidayakan petani dengan memperhatikan aspek-aspek ekologi, ekonomi dan budaya serta kerusakan lingkungan dengan pemanfaatan teknologi tanaman refugia untuk konservasi musuh alami dan pengendalian hama secara hayati.

Kegiatan PPM dilaksanakan di ruang pertemuan Gapoktan Bunga Karang Desa Karang Bunga Kecamatan Madastana Kabupaten Barito Kuala Kalimantan Selatan. Demonstrasi dilaksanakan di lahan petani. Khalayak sasaran yang hadir berasal dari pengurus dan anggota Gapoktan Bunga Karang yang berjumlah 20 orang yang terdiri dari laki-laki dan perempuan. Disamping itu Tim juga mengajak mahasiswa yang mengambil mata kuliah Hama dan Penyakit pertanian untuk terlibat dalam kegiatan tersebut.

Sosialisai melalui penyuluhan secara umum dalam pengendalian hama mencakup:

- Rekayasa ekologi dengan memanfaatkan tanaman/tumbuhan refugia sebagai agen pengendali yang aman bagi petani, konsumen dan lingkungan.

- Pengendalian dengan cara bercocok tanam

- Pengendalian secara fisik/mekanik

- Pengendalian secara biologi

- Pengendalian menggunakan pestisida organik

- Pengenalan jenis serangga baik sebagai hama maupun musuh alami

- Keterampilan dalam penilaian serangan akibat hama tanaman padi

Acara diskusi berlangsung dengan baik dan peserta sangat antusias mengikutinya sehingga permasalahpermasalahan yang mereka hadapi bisa terungkap terutama masalah serangan hama padi dan teknik pengendaliannya. Rata-rata petani belum mengetahui teknik pengendalian hama padi dengan menggunakan tanaman Refugia karena memang refugia adalah teknologi baru dalam dunia pertanian khususnya di Desa Karang Bunga Kecamatan Madastana Kabupaten Barito Kuala Kalimantan Selatan, yaitu sistem pengendalian hama dengan memanfaatkan tanaman hias di lahan pertanian. Refugia adalah tanaman yang berfungsi sebagai mikrohabitat dari serangga musuh alami dan penarik hama tanaman. Refugia dapat menarik 
serangga parasitoid dan predator untuk datang memakan nektar dan polen, selain itu juga dapat menjadi tempat berlindung bagi predator dan parasitoid tersebut.

Teknik Refugia lebih tergolong ekonomis dan juga tentu lebih ramah lingkungan dan kesehatan, karena dengan menggunakan teknik ini kita tidak menggunakan bahan-bahan kimia yang justru merugikan kesehatan.

Adanya tanaman hias di pinggir sawah, musuh alami tersebut lebih sehat dan daya hidupnya lebih lama. Saat menyerang OPT (Organisme Pengganggu Tanaman) pun lebih gesit dibanding tidak ada refugia, karena musuh alami hanya mengkonsumsi pakan dari pinggir sawah. Musuh alami tersebut menjadi sahabat petani dalam menyerang hama tanaman. Penerapan pengendalian hayati membutuhkan lingkungan biotik maupun abiotik yang optimal. Tumbuhan Refugia yang dibudidayakan di sekitar tanaman menjadi mikro habitat bagi musuh alami (parasitoid maupun predator).

Banyak jenis tanaman hias sebagai sumber pakan langsung bagi musuh alami (nektar dan polen), dan secara tidak langsung menyediakan mangsa dan inang, di samping mengelola iklim mikro yang sesuai dengan kebutuhan hidup musuh alami. Musuh alami baik parasitoid dan predator yang memanfaatkan nektar dan polen tumbuhan tersebut, akan meningkat laju reproduksi (fekunditas)nya, sehingga telur yang dihasilkan lebih banyak. Dengan demikian, populasi musuh alami akan meningkat pula, sehingga potensi sebagai pengendali alami hama tanaman padi pun akan meningkat yang menyebabkan populasi hama hama tanaman padi dapat ditekan sampai keseimbangan umum.

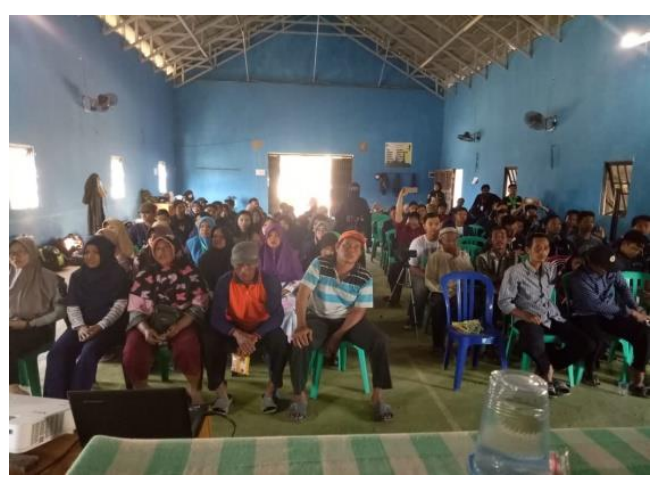

Gambar 1. Peserta Program PPM

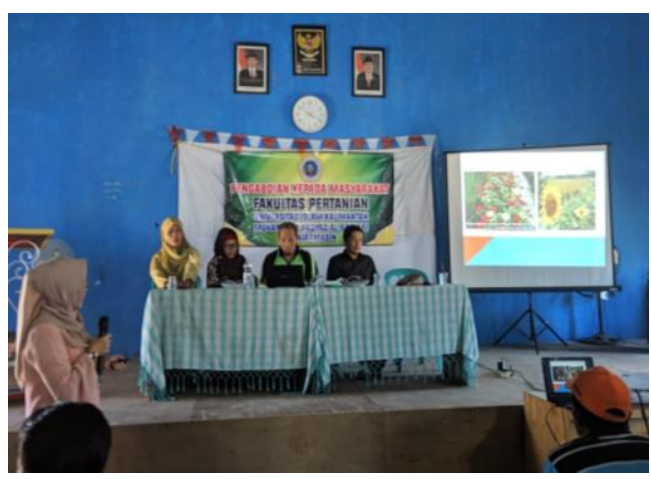

Gambar 2. Narasumber sedang memberikan materi 


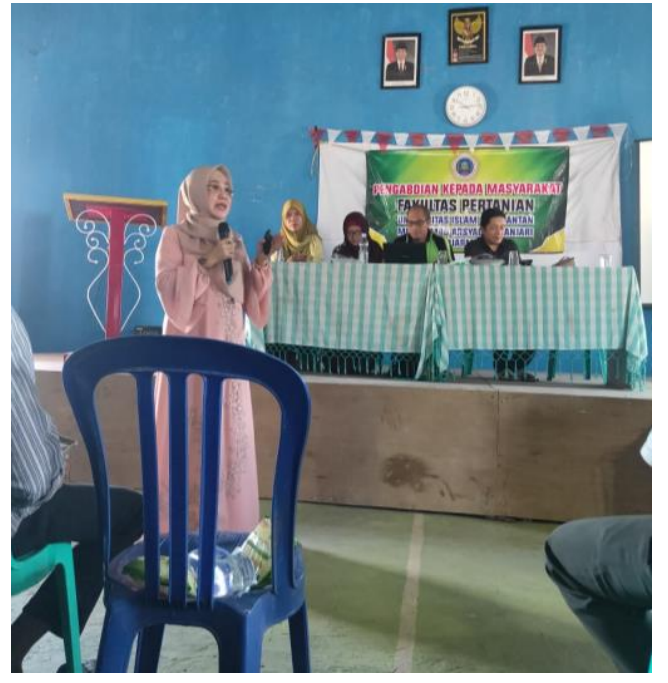

Gambar 3. Diskusi dengan peserta

Refugia yang digunakan adalah kembang kertas (Zinnia elegans Jaqc.) yang merupakan salah satu tanaman dari genus Zinnia yang paling banyak dikenal. Tanaman ini merupakan asli Amerika yang berasal dari Meksiko. Tanaman hias ini sebelumnya kurang diperhatikan yang pada akhirnya biji tanaman ini dibawa ke Royal Botanical Garden di Madrid pada tahun 1790 dari Meksiko. Kembang kertas merupakan tanaman annual yang tersebar secara luas di dunia. Tanaman ini sering digunakan sebagai tanaman hias di pekarangan rumah dan bunga potong. Spesies ini mampu tumbuh di daerah tropis dan subtropis dengan ketinggian hingga $1800 \mathrm{~m}$ (Stimart \& Boyle, 2007). Dengan keunggulan seperti bentuk bunga yang bagus, postur tanaman tegak, serta mampu tumbuh sepanjang tahun, maka kembang kertas banyak dikembangkan di berbagai negara (Muzaki, 2018).

Kelebihan bunga kertas, selalu mekar dan bunganya beraneka warna sehingga banyak dikunjungi serangga dari berbagai jenis kupu-kupu, semut, kumbang, laba-laba dan lebah. Kelebihan lain tanaman ini mudah ditanam (cepat tumbuh), bibit mudah diperoleh, regenerasi tanaman tergolong cepat dan kontinyu.

\section{Demontrasi Penanaman Tanaman}

\section{Refugia}

Setelah mendapatkan pengetahuan tentang tanaman refugia, petani mulai menanam tanaman refugia di lahan sawah mereka dibantu oleh Tim. Refugia yang digunakan adalah kembang kertas (Zinnia elegans Jaqc.) yang berwarna merah, pink dan putih. Penanaman tanaman refugia ini akan mendapatkan dua fungsi yaitu sebagai agen pengendali hama terutama wereng dan penggerek batang padi dan sebagai strategi efektif untuk meningkatkan keragaman hayati dan kekayaan ekosistem pada lahan padi. 


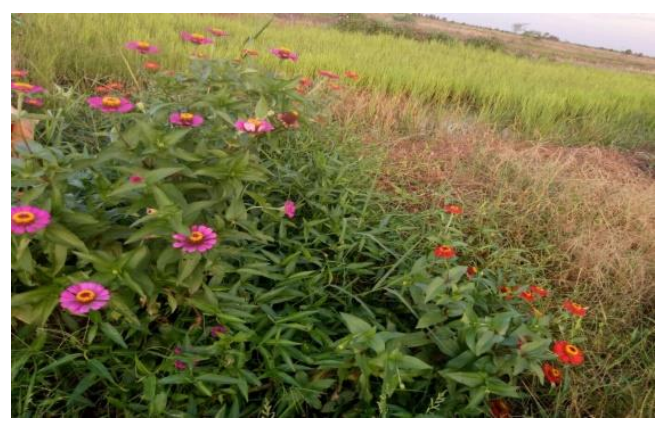

Gambar 4. Tanaman Refugia Jenis Kembang Kertas (Zinnia elegans Jaqc.) yang di tanam di Galangan Sawah

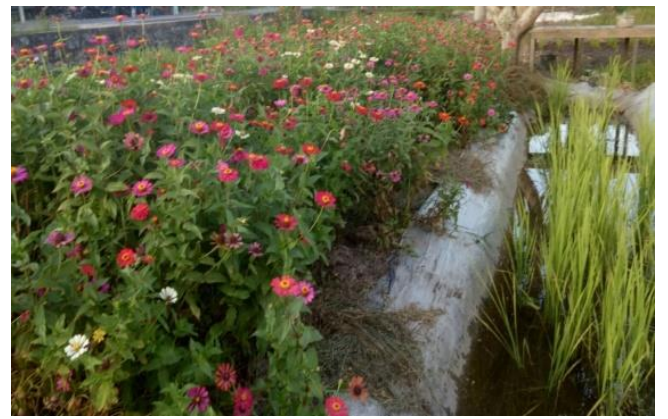

Gambar 5. Jenis Kembang Kertas dengan warna Merah, Pink dan Putih (Zinnia elegans Jaqc.)

\section{Evaluasi Kegiatan}

Hasil evaluasi kegiatan Sosialisasi melalui penyuluhan ini didapat dari kuesioner yang diberikan kepada peserta pelatihan baik sebelum dan sesudah kegiatan dilaksanakan. Tabel 4. merupakan hasil evaluasi yang didapat sebelum dilaksanakan Sosialisasi

Tabel 4. Hasil Evaluasi Sebelum Kegiatan

\begin{tabular}{clcc}
\hline \multirow{2}{*}{ No. } & \multicolumn{1}{c}{ Pertanyaan } & \multicolumn{2}{c}{ Jawaban Responden } \\
\cline { 3 - 4 } & \multicolumn{1}{c}{ Ya } & Tidak \\
\hline 1. & $\begin{array}{l}\text { Apakah pernah dilakukan penyuluhan tentang Refugia? } \\
\text { 2. } \begin{array}{l}\text { Apakah anda mengetahui jenis tanaman berbunga yang } \\
\text { sebenarnya dapat digunakan sebagai tanaman refugia }\end{array}\end{array}$ & 20 & 0 \\
3. $\begin{array}{l}\text { Apakah anda mengetahui manfaat tanaman refugia } \\
\text { sebagai agen pengendali hama tanaman padi }\end{array}$ & 0 & 20 \\
4. $\begin{array}{l}\text { Apakah anda sudah pernah menanam tanaman berbunga } \\
\text { dipekarangan rumah? }\end{array}$ & 12 & 8 \\
& $\begin{array}{l}\text { Apakah anda mengetahui keuntungan penggunaan } \\
\text { tanaman refugia sebagai agen pengendali hama tanaman } \\
\text { padi? }\end{array}$ & 1 & 19 \\
6. Apakah anda mengetahui perbedaan antara & 0 & 20
\end{tabular}


pengendalian hama dengan menggunakan pestisida dengan pengendalian hama dengan menggunakan tanaman refugia?

Apakah di Desa anda sudah ada teknik pengendalian

7. hama tanaman padi yang aman bagi manusia dan

lingkungannya?

Apakah anda mengetahui dampak negative dari

8. penggunaan pestisida kimia dalam mengendalikan hama tanaman padi?

Apakah anda mengetahui kendala yang dihadapi dalam

9. proses pemanfaatan tanaman refugia sebagai agen pengendali hayati untuk tanaman padi?

Apakah anda mengetahui banyak sekali jenis tanaman

10. berbunga dan gulma yang berbunga disekitar lingkungan anda yang dapat dimanfaatkan sebagai refugia?

Berdasarkan hasil kuesioner yang diberikan kepada peserta kegiatan PPM, diperoleh gambaran bahwa masyarakat peserta kegiatan PPM tersebut belum banyak mengetahui dan mendapatkan pengetahuan tentang jenis tanaman berbunga dan jenis gulma berbunga yang dapat dimanfaatkan sebagai tanaman refugia untuk pengendali hama tanaman padi yang ramah lingkungan. Hal tersebut terlihat bahwa tidak ada satu orangpun yang pernah mendapatkan penyuluhan/informasi tentang tanaman refugia sebagai agen pengendali hama padi yang ramah lingkungan, sehingga dapat disimpulkan bahwa teklologi pengendalian hama padi dengan menggunakan tanaman refugia merupakan teknologi baru bagi Gapoktan Bunga Karang Desa Karang Bunga Kecamatan Madastana Kabupaten Barito Kuala Kalimantan Selatan. Berdasarkan Tabel 4. sangat jelas sekali bahwa rata-rata peserta PPM sangat minim sekali bahkan tidak tahu sama sekali tentang tanaman refugia sebagai agen pengendali hama padi yang aman bagi manusia dan lingkungan. Setelah pelaksanaan penyuluhan dan demonstrasi tentang tanaman refugia selesai dilaksanakan kemudian dilakukan evaluasi untuk mengetahui tingkat pemahaman peserta pelatihan. Hasil evaluasi setelah kegiatan PPM disajikan pada Tabel 5. 
Tabel 5. Hasil Evaluasi setelah Kegiatan PPM

\begin{tabular}{|c|c|c|c|}
\hline \multirow{2}{*}{ No. } & \multirow{2}{*}{ Pertanyaan } & \multicolumn{2}{|c|}{ Jawaban Responden } \\
\hline & & $\mathrm{Ya}$ & Tidak \\
\hline 1. & $\begin{array}{l}\text { Apakah pernah dilakukan sosialisasi melalui penyuluhan } \\
\text { dan demostrasi tentang pemanfaatan tanaman refugia } \\
\text { sebagai agen pengendali hama padi? }\end{array}$ & 20 & 0 \\
\hline 2. & $\begin{array}{l}\text { Apakah anda mengetahui jenis tanaman berbunga dan } \\
\text { gulma berbunga yang dapat dipergunakan sebagai } \\
\text { tanaman/tumbuhan refugia? }\end{array}$ & 20 & 0 \\
\hline 3. & $\begin{array}{l}\text { Apakah anda mengetahui bagaimana cara pemanfaatan } \\
\text { tanaman/tumbuhan refugia sebagai teknologi baru dalam } \\
\text { pengendalian hama padi yang ramah lingkungan? }\end{array}$ & 20 & 0 \\
\hline 4. & $\begin{array}{l}\text { Apakah anda mendapatkan tambahan teknologi baru } \\
\text { yang ramah lingkungan dalam mengendalikan hama } \\
\text { tanaman padi? }\end{array}$ & 20 & 0 \\
\hline 5. & $\begin{array}{l}\text { Apakah anda akan mengadopsi teknologi baru berupa } \\
\text { pemanfaatan tanaman/tumbuhan refugia sebagai agen } \\
\text { pengendali hama padi yang ramah lingkungan di area } \\
\text { persawahan? }\end{array}$ & 19 & 1 \\
\hline 6. & $\begin{array}{l}\text { Apakah anda sudah mengetahui perbedaan antara } \\
\text { penggunaan pestisida dengan teknologi menggunakan } \\
\text { tanaman/tumbuhan refugia? }\end{array}$ & 19 & 1 \\
\hline 7. & $\begin{array}{l}\text { Apakah di Desa anda sudah ada tumbuhan/tanaman } \\
\text { yang berpotensi sebagai tanaman/tumbuhan refugia? }\end{array}$ & 20 & 0 \\
\hline 8. & $\begin{array}{l}\text { Apakah anda mengetahui manfaat penggunaan teknologi } \\
\text { refugia sebagai pengendali hama padi yang ramah } \\
\text { lingungan? }\end{array}$ & 20 & 0 \\
\hline 9. & $\begin{array}{l}\text { Apakah anda mengetahui kendala yang dihadapi dalam } \\
\text { proses penggunaan teknologi tanaman refugia? }\end{array}$ & 20 & 0 \\
\hline 10 & $\begin{array}{l}\text { Apakah anda akan segera menggunakan/memanfaatkan } \\
\text { teknologi tanaman refugia yang di tanam di galangan } \\
\text { sawah sebagai agen pengendali hama padi yang ramah } \\
\text { lingkungan? }\end{array}$ & 20 & 0 \\
\hline
\end{tabular}

Berdasarkan Tabel 5. menunjukan bahwa semua peserta PPM sebanyak 20 orang sudah mengetahui dan ikut terlibat dalam pemanfaatan tanaman/tumbuhan refugia sebagai teknologi baru bagi Gapoktan Bunga

Karang Desa Karang Bunga Kecamatan

Mandastana Kabupaten Barito Kuala

Kalimantan Selatan yang ramah

lingkungan. Bahkan semua peserta 
akan meaplikasikan pengendalian hama padi dengan teknologi tanaman refugia yang ramah lingkungan ini. Hal ini sesuai dengan

Ada 20 petani yang sudah memahami manfaat dan kendala dalam pemanfaatan teknologi baru dalam pengendalian hama padi yang ramah lingkungan berupa tanaman refugia, artinya ada peningkatan keterampilan dan pengetahuan tentang teknologi refugia bagi peserta pelatihan apabila petani tersebut diberi Ada 20 orang petani yang rencananya akan memanfaatkan teknologi tanaman refugia pada areal persawahan mereka.

Peserta PPM sebanyak 19 orang sudah mengetahui perbedaan antara penggunaan pestisida kimia sintetis dengan pemanfaatan teknologi tanaman refugia untuk mengendalikan hama padi dan terdapat 1 orang peserta yang belum memahami perbedaan tersebut. Hal tersebut diduga karena petani yang 1 orang terbut berperilaku sebagai pestisida sintetik minded sehingga tidak mudah untuk merubah perilaku petani yang seperti itu.

Kegiatan PPM berjalan lancar, hal tersebut tidak terlepas dari peran peserta PPM yang secara antusias mengikuti pelatihan dan demostrasi serta menyimak dengan baik materi yang disampaikan terbukti dari tingkat kehadiran peserta yang tinggi sampai $100 \%$.

\section{KESIMPULAN DAN SARAN}

Kesimpulan

Berdasarkan hasil kegiatan Program Pemberdayaan Masyarakat (PPM) yang telah dilaksanakan dapat disimpulkan sebagai berikut:

1. Pengetahuan peserta PPM yang berasal dari Gapoktan Bunga Karang Desa Karang Bunga Kecamatan Mandastana Kabupaten Barito Kuala Kalimantan Selatan mengalami peningkatan dalam hal pengetahuan tentang pemanfaatan teknologi tanaman refugia untuk mengendalikan hama tanaman padi yang ramah lingkungan.

2. Peserta PPM mendapatkan keterampilan dalam memanfaatkan teknologi tanaman refugia dalam pengendalian hama tanaman padi yang ramah lingkungan.

3. Beberapa peserta PPM sudah mulai memanfaatan teknologi tanaman refugia dengan menanami galangan sawah mereka dengan kembang kertas (Zinnia elegans Jaqc.) warna merah, pink dan putih. 


\section{Saran-saran}

Perlu dilakukan pembinaan kepada petani yang selalu menggunakan pestisida sintetik dalam mengendalikan hama tanaman padinya agar pelanpelan dapat beralih menggunakan teknik pengendalian hama padi yang aman dan ramah lingkungan seperti pemanfaatan tanaman refugia.

\section{DAFTAR PUSTAKA}

Borror, D.J. nd R.E. White. 1970. A Field Guide to the Insects of America North of Mexico. Hoghton Muffin Company, Boston.

Borror, D.J., C.A. Triplehorn \& N.F. Johnson. 1992. Pengenalan Pelajaran Serangga (Diterjemahkan oleh Soetiyono Partosoedjono). Gadjah Mada University Press, Yogyakarta.

Darmania, U. 2017. Pemanfaatan Tanaman Refugia untuk Mengendalikan Hama dan Penyakit Tanaman Padi. Buletinikatan. Vol 7(2).

Kurniawati,N. \& E., Martono. 2015. Peran Tumbuhan Berbunga Sebagai Media Konservasi Artropoda Musuh Alami. Jurnal Perlindungan Tanaman Indonesia. Vol. 19( 2) : 53-59.

Muzaki K. 2018. Mengenal Refugia, Tanaman Bunga Cantik yang Bisa Kendalikan Hama, https://jateng.tribunnews.com/201 8/11/07/mengenal-refugia-

tanaman-bunga-cantikpengendali-hama.

Mahmud, T. 2006. Identifikasi Serangga di sekitar Tumbuhan Kangkung (Ipomoeas crassicaulis RooB).Skripsi.Universitas Islam Negeri Malang.

Prabaningrum, L. 2015. Empat Prinsip Dasar dalam Penerapan Pengendalian Hama Terpadu (PHT).(balitsa.litbang.pertanian.g o.id.), Diakses 12 Juli 2019.

Rachmawati, N., Susilawati, Eva, P. 2019. Pengolahan Sampah Organik Menjadi Kompos Untuk Mendukung Kampung Pro Iklim. Jurnal Al-Ikhlas Volume 4 (2): 124-132

Rostini, T., Muhammad, I.Z., \& Danang, B. 2019. Peningkatan Nilai Ekonomis Limbah Pertanian Di Pedesaan Melalui Tekhnologi Bokashidikelompok Tani Martapura, Kabupaten Banjar. Jurnal Al-Ikhlas Volume 4 (2): 104-112

Sakir, I.M., dan Desinta. 2018. Pemanfaatan Refugia dalam Meningkatkan Produksi Tanaman Padi Berbasis Kearifan Lokal. Jurnal Lahan Suboptimal: Journal of Suboptimal Lands. Vol . 7(1): 97-105.

Septariani, D.N.,, Aktavia, H, dan Mujiyo. 2017. Pemanfaatan Berbagai Tanaman Refugia Sebagai Pengendali Hama Alami Pada Tanaman Cabai (Capsicum Annum L.). https://jurnal.uns.ac.id/prima/inde $\underline{x}$. 